\title{
Effect of Cerium (Ce) on the Redox States of Ascorbate and Glutathione through Ascorbate-glutathione Cycle in the Roots of Maize Seedlings under Salt Stress
}

\author{
H. $\mathrm{HU}^{1,2}$ and C. SHAN ${ }^{1,2 *}$ \\ ${ }^{1}$ Henan Institute of Science and Technology, Xinxiang, Henan, 453003, China \\ ${ }^{2}$ Collaborative Innovation Center of Modern Biological Breeding, Henan Province, Xinxiang, 453003 China
}

(Received 12 February 2017; Accepted 8 June 2017;

Communicated by S. Gottwald)

This study investigated the effect of cerium (Ce) on the ascorbate-glutathione (AsAGSH) cycle in the roots of maize seedlings under salt stress. The results showed that salt stress significantly increased the activities of ascorbate peroxidase (APX) and monodehydroascorbate reductase (MDHAR), malondialdehyde (MDA) content and electrolyte leakage (EL) in the roots of maize seedlings, compared to the control. However, salt stress significantly decreased plant height, dry weight of root and shoot, the activities of glutathione reductase (GR) and dehydroascorbate reductase (DHAR), and the ratios of AsA/DHA and GSH/GSSG in the roots of maize seedlings, compared to the control. Pretreatment with cerium nitrate $\left(\mathrm{Ce}\left(\mathrm{NO}_{3}\right)_{3}\right)$ significantly increased plant height, dry weight of root and shoot, the activities of above four enzymes, and the ratios of AsA/DHA and GSH/GSSG under salt stress, compared to salt stress alone. Pretreatment with $\mathrm{Ce}\left(\mathrm{NO}_{3}\right)_{3}$ significantly decreased MDA content and EL induced by salt stress, compared to salt stress alone. Meanwhile, application of $\mathrm{Ce}\left(\mathrm{NO}_{3}\right)_{3}$ to the control also significantly increased plant height, dry weight of root and shoot, the activities of above four enzymes and the ratios of AsA/DHA and GSH/GSSG, and decreased MDA content and EL, compared with control. Our results suggested that $\mathrm{Ce}\left(\mathrm{NO}_{3}\right)_{3}$ alleviated salt stress-induced oxidative damage by improving AsA-GSH cycle in maize roots.

Keywords: salt stress, cerium nitrate, ascorbate-glutathione cycle, maize, root

Abbreviations: APX - ascorbate peroxidase; GR - glutathione reductase; DHAR dehydroascorbate reductase; MDHAR - monodehydroascorbate reductase; GSH - reduced glutathione; AsA - reduced ascorbic acid; MDA - malondialdehyde; EL - electrolyte leakage

\section{Introduction}

Salt stress has adverse effects on plant growth, productivity and survival (Muchate et al. 2016). Salt stress often results in a substantial accumulation of reactive oxygen species (ROS), which exceeds the capacity of ROS-scavenging system and results in oxidative

\footnotetext{
*Corresponding author; E-mail: shchjuan1978@aliyun.com.
} 
damage to plants (Hu et al. 2012; Liu et al. 2012; Yousuf et al. 2017). Plants have an intricate antioxidant defense system to protect against the harmful effects of oxidative damage. Ascorbate-glutathione (AsA-GSH) cycle is an important component of antioxidant defense system in plants (Shan et al. 2015). In this cycle, there are four enzymes, including ascorbate peroxidase (APX), monodehydroascorbate reductase (MDHAR), dehydroascorbate reductase (DHAR) and glutathione reductase (GR). APX can clear away $\mathrm{H}_{2} \mathrm{O}_{2}$ by using reduced ascorbate (AsA) as electron donor. MDHAR and DHAR can reduce monodehydroascorbate and dehydroascorbate to AsA, respectively. GR can reduce oxidized glutathione (GSSG) to reduced glutathione (GSH). Therefore, AsA-GSH cycle has an important roles in regulating the redox states of antioxidants ascorbate and glutathione and clearing away $\mathrm{H}_{2} \mathrm{O}_{2}$, which results in the defense against oxidative damage.

Rare earth elements have many important roles in regulating plant growth and the responses of plants to stresses (Shan and Zhao 2014; Dai et al. 2016). It has been documented that cerium $(\mathrm{Ce})$ is an important rare earth element, which can protects plants against a variety of environmental stresses, including copper stress, cadmium stress, UV-B stress and salt stress (Mao et al. 2012; Wu et al. 2014; Liu et al. 2016; Rossi et al. 2016). Increasing evidences showed that Ce had important roles in fighting against oxidative damage induced by various stresses (Wu et al. 2014; Liu et al. 2016). It has been documented that Ce could enhance AsA-GSH cycle under copper stress (Liu et al. 2016). As we all known, salinity in soil affects the roots of plants first (Jouyban 2012). However, little is known about AsA-GSH cycle in the roots of plants to Ce under salt stress. Thus, it is very interesting to elucidate whether and how Ce regulates AsA-GSH cycle in the roots of plants under salt stress.

In this study, we investigated the effects of cerium nitrate $\left(\mathrm{Ce}\left(\mathrm{NO}_{3}\right)_{3}\right)$ on the activities of enzymes involved in AsA-GSH cycle, the ratios of AsA/DHA and GSH/GSSG, and malondialdehyde (MDA) content and electrolyte leakage (EL) of maize roots exposed to salt stress. The aim of the study was to elucidate whether and how $\mathrm{Ce}\left(\mathrm{NO}_{3}\right)_{3}$ regulates AsA-GSH cycle in maize roots under salt stress, and provide new knowledge to the role of $\mathrm{Ce}\left(\mathrm{NO}_{3}\right)_{3}$ in promoting salt tolerance of maize crop.

\section{Materials and Methods}

\section{Plant material, growth conditions and treatments}

Maize (Zea mays L., Xindan29) seeds were germinated in Petri dishes with filter paper moistened with distilled water and grown in artificial climate chamber under a day/night temperature of $25 / 15^{\circ} \mathrm{C}, 500 \mu \mathrm{mol} \mathrm{m} \mathrm{m}^{-2} \mathrm{~s}^{-1}$ photosynthetic active radiation and a $12-\mathrm{h}$ photoperiod. When the first leaf was fully expanded, the seedlings were transferred into plastic boxes filled with full-strength Hoagland's solution and kept their roots in dark. The Hoagland's solution was exchanged every 3 days. When the third leaf was fully expanded, the seedlings with similar height and growth conditions were selected for our experiments. To study the effect of salt stress, the roots were placed in beakers containing $100 \mathrm{ml} 100 \mathrm{mM} \mathrm{NaCl}$ solution and wrapped with aluminium foil under above conditions. 
To study the effect of $\mathrm{Ce}\left(\mathrm{NO}_{3}\right)_{3}$, a group of plants were pretreated with $30 \mu \mathrm{M} \mathrm{Ce}\left(\mathrm{NO}_{3}\right)_{3}$ (a suitable concentration selected from $10,30,50$ and $\left.70 \mu \mathrm{M} \mathrm{Ce}\left(\mathrm{NO}_{3}\right)_{3}\right)$ for $12 \mathrm{~h}$ and then exposed to salt stress. The control plants were treated with Hoagland's solution alone. After treatment of $48 \mathrm{~h}$, the roots of maize seedlings were collected and frozen in liquid nitrogen, and then kept at $-80{ }^{\circ} \mathrm{C}$ until analyses. After treatment of $168 \mathrm{~h}$, the dry weight of maize seedling was measured.

Analysis of ascorbate peroxidase, glutathione reductase, dehydroascorbate reductase, and monodehydroascorbate reductase

Enzymes were extracted according to Grace and Logan (1996) with some modifications. Each frozen sample $(0.5 \mathrm{~g})$ was ground into a fine powder in liquid $\mathrm{N}_{2}$ with a mortar and pestle. Fine powder was homogenized in $6 \mathrm{ml} 50 \mathrm{mM} \mathrm{KH}_{2} \mathrm{PO}_{4}(\mathrm{pH} 7.5)$ containing 0.1 $\mathrm{mM}$ ethylenediaminetetraacetic acid, $0.3 \%(\mathrm{v} / \mathrm{v})$ Triton $\mathrm{X}-100$, and $1 \%(\mathrm{w} / \mathrm{v})$ soluble polyvinylpolypyrrolidone, with the addition of $1 \mathrm{mM}$ AsA in the case of the APX assay. The extract was immediately centrifuged at $13,000 \times g$ for $15 \mathrm{~min}$ at $2{ }^{\circ} \mathrm{C}$. The supernatant was then used immediately for measuring the following enzymes. Ascorbate peroxidase (APX, EC 1.11.1.11) activity was measured by monitoring the decrease in absorbance at $290 \mathrm{~nm}$ (Nakano and Asada 1981). One unit of enzyme was defined as the amount of APX catalyzing the oxidation of $1 \mu \mathrm{mol}$ ascorbate per minute. Glutathione reductase (GR, EC 1.6.4.2) activity was monitored at $340 \mathrm{~nm}$ (Grace and Logan 1996). One unit of GR activity was defined as the reduction of $1 \mu \mathrm{mol}$ NADPH per minute. Monodehydroascorbate reductase (MDHAR, EC 1.6.5.4) activity was assayed at $340 \mathrm{~nm}$ (Miyake and Asada 1992). One unit of MDHAR activity was defined as the amount of enzyme that oxidizes $1 \mu \mathrm{mol}$ NADH per minute. Dehydroascorbate reductase (DHAR, EC 1.8.5.1) activity was measured at $265 \mathrm{~nm}$ (Dalton et al. 1986). One unit of DHAR activity was defined as the amount of enzyme that produces $1 \mu \mathrm{mol}$ AsA per minute. The specific activities of above enzymes (APX, GR, DHAR and MDHAR) were expressed as units $\mathrm{mg}^{-1}$ protein. Protein concentration was measured by using bovine serum albumin (BSA) as the standard according to Bradford (1976).

\section{Analysis of AsA/DHA and GSH/GSSG}

AsA and DHA were measured according to Hodges et al. (1996). The ratio between the content of AsA and the content of DHA was expressed as AsA/DHA. The contents of GSSG and GSH were measured according to Griffith (1980). The ratio between the content of GSH and the content of GSSG was expressed as GSH/GSSG.

\section{Measurement of MDA content and EL}

MDA content was measured by thiobarbituric acid (TBA) reaction according to Hodges et al. (1999). EL was determined according to Zhao et al. (2004). EL was expressed as the relative ion leakage, a percentage of the total conductivity after boiling. 
Analysis of plant height, root dry weight and aboveground dry weight

After $168 \mathrm{~h}$ of treatment, the plant height was measured by a ruler. Root dry weight and aboveground dry weight were measured by oven drying method.

\section{Statistical analysis}

The whole experiment repeated 3 times with 6 seedlings per treatment each time. The results presented were the mean values of 3 replications. Means were compared by oneway analysis of variance and Duncan's multiple range test at the 5\% level of significance. The correlation analysis of parameters was done by SPSS 19.0 (Chicago, USA).

\section{Results}

\section{The selection of suitable $\mathrm{Ce}\left(\mathrm{NO}_{3}\right)_{3}$ treatment concentration}

In order to select a suitable $\mathrm{Ce}\left(\mathrm{NO}_{3}\right)_{3}$ treatment concentration, we investigated the effects of different concentrations of $\mathrm{Ce}\left(\mathrm{NO}_{3}\right)_{3}$ on the ratios of AsA/DHA and GSH/GSSG under salt stress. The $\mathrm{Ce}\left(\mathrm{NO}_{3}\right)_{3}$ concentrations are $10,30,50$ and $70 \mu \mathrm{M}$, respectively. The results showed that salt stress alone significantly decreased the ratios of AsA/DHA and GSH/GSSG, compared to the control (Table 1). Compared to salt stress alone, application of $10,30,50$ and $70 \mu \mathrm{M} \mathrm{Ce}\left(\mathrm{NO}_{3}\right)_{3}$ to $\mathrm{NaCl}$-treated seedlings increased the ratio of AsA/ DHA by $10.8 \%, 27.3 \%, 21.6 \%$ and $14.2 \%$, respectively. Compared to salt stress alone, application of 10,30, 50 and $70 \mu \mathrm{M} \mathrm{Ce}\left(\mathrm{NO}_{3}\right)_{3}$ to $\mathrm{NaCl}$-treated seedlings increased the ratio of GSH/GSSG by $11.7 \%, 22.2 \%, 17.2 \%$ and $10.5 \%$, respectively. Application of 30 $\mu \mathrm{M} \mathrm{Ce}\left(\mathrm{NO}_{3}\right)_{3}$ significantly increased the ratios of AsA/DHA and GSH/GSSG under salt stress, compared to other concentrations of $\mathrm{Ce}\left(\mathrm{NO}_{3}\right)_{3}$. These results suggested that $30 \mu \mathrm{M}$ $\mathrm{Ce}\left(\mathrm{NO}_{3}\right)_{3}$ was a suitable concentration to study the effect of $\mathrm{Ce}\left(\mathrm{NO}_{3}\right)_{3}$ on AsA-GSH cycle in maize seedlings roots under salt stress.

Table 1. Effects of different concentrations of $\mathrm{Ce}\left(\mathrm{NO}_{3}\right)_{3}$ on the ratios of AsA/DHA and GSH/GSSG in the roots of maize seedlings under salt stress

\begin{tabular}{|c|c|c|c|c|c|c|}
\hline Parameters & Control & \multirow{2}{*}{$\mathrm{NaCl}$} & $\begin{array}{c}10 \mu \mathrm{M} \mathrm{Ce}+ \\
\mathrm{NaCl}\end{array}$ & $\begin{array}{c}30 \mu \mathrm{M} \mathrm{Ce}+ \\
\mathrm{NaCl}\end{array}$ & $\begin{array}{c}50 \mu \mathrm{M} \mathrm{Ce}+ \\
\mathrm{NaCl}\end{array}$ & $\begin{array}{c}70 \mu \mathrm{M} \mathrm{Ce}+ \\
\mathrm{NaCl}\end{array}$ \\
\hline AsA/DHA & $23.3 \pm 2.75 \mathrm{a}$ & $16.6 \pm 1.73 \mathrm{~d}$ & $18.5 \pm 1.84 \mathrm{c}$ & $21.4 \pm 2.66 \mathrm{~b}$ & $20.4 \pm 2.47 \mathrm{bc}$ & $19.1 \pm 2.35 \mathrm{c}$ \\
\hline GSH/GSSG & $24.1 \pm 3.11 \mathrm{a}$ & $18.0 \pm 2.08 \mathrm{~d}$ & $20.1 \pm 2.39 \mathrm{c}$ & $22.0 \pm 2.80 \mathrm{~b}$ & $21.1 \pm 2.11 \mathrm{bc}$ & $19.9 \pm 2.14 \mathrm{c}$ \\
\hline
\end{tabular}

Note: The plants were treated as follows: Control, full-strength Hoagland's solution; $\mathrm{NaCl}, 100 \mathrm{mM} \mathrm{NaCl} ; 10 \mu \mathrm{M}$ $\mathrm{Ce}+\mathrm{NaCl}, 10 \mu \mathrm{M} \mathrm{Ce}\left(\mathrm{NO}_{3}\right)_{3}+100 \mathrm{mM} \mathrm{NaCl} ; 30 \mu \mathrm{M} \mathrm{Ce}+\mathrm{NaCl}, 30 \mu \mathrm{M} \mathrm{Ce}\left(\mathrm{NO}_{3}\right)_{3}+100 \mathrm{mM} \mathrm{NaCl} ; 50 \mu \mathrm{M} \mathrm{Ce}+\mathrm{NaCl}, 50 \mu \mathrm{M}$ $\mathrm{Ce}\left(\mathrm{NO}_{3}\right)_{3}+100 \mathrm{mM} \mathrm{NaCl} ; 70 \mu \mathrm{M} \mathrm{Ce}+\mathrm{NaCl}, 70 \mu \mathrm{M} \mathrm{Ce}\left(\mathrm{NO}_{3}\right)_{3}+100 \mathrm{mM} \mathrm{NaCl}$. The plants were pretreated with $\mathrm{Ce}\left(\mathrm{NO}_{3}\right)_{3}$ for $12 \mathrm{~h}$, and then exposed to $100 \mathrm{mM} \mathrm{NaCl}$ for $48 \mathrm{~h}$. Values represent mean \pm standard deviations (SD) of five replicates for each treatment, different letters indicate statistical difference at $P<0.05$ in the same row. 
Effects of $\mathrm{Ce}\left(\mathrm{NO}_{3}\right)_{3}$ on the activities of enzymes in AsA-GSH cycle in the roots of maize seedlings under salt stress.

As shown in Table 2, compared with control, salt stress increased the activities of APX and MDHAR by $50 \%$ and $72.8 \%$, and decreased the activities of GR and DHAR by $35.4 \%$ and $34.8 \%$, respectively. Compared with salt stress alone, application of $\mathrm{Ce}\left(\mathrm{NO}_{3}\right)_{3}$ to NaCl-treated seedlings increased the activities of APX, GR, DHAR and MDHAR by $20 \%, 160 \%, 133.3 \%$ and $31.4 \%$ after $48 \mathrm{~h}$ of treatment, respectively. Meanwhile, pretreatment with $\mathrm{Ce}\left(\mathrm{NO}_{3}\right)_{3}$ alone also significantly increased the activities of above enzymes, compared with control. These results suggested that $\mathrm{Ce}\left(\mathrm{NO}_{3}\right)_{3}$ could up-regulate AsA-GSH cycle through APX, GR, DHAR and MDHAR in the roots of maize seedlings under salt stress.

\section{Effects of $\mathrm{Ce}\left(\mathrm{NO}_{3}\right)_{3}$ on the redox states of ascorbate and glutathione} in the roots of maize seedlings under salt stress

Compared with control, salt stress decreased the ratios of AsA/DHA and GSH/GSSG by $20.4 \%$ and $23.4 \%$, respectively (Table 2). Pre-treatment with $\mathrm{Ce}\left(\mathrm{NO}_{3}\right)_{3}$ significantly increased the ratios of AsA/DHA and GSH/GSSG under salt stress, compared to salt stress alone. After $48 \mathrm{~h}$ of treatment, application of $\mathrm{Ce}\left(\mathrm{NO}_{3}\right)_{3}$ to $\mathrm{NaCl}$-treated seedlings increased the ratios of AsA/DHA and GSH/GSSG by $12.8 \%$ and $18.6 \%$, respectively. Meanwhile, pretreatment with $\mathrm{Ce}\left(\mathrm{NO}_{3}\right)_{3}$ alone also significantly increased the ratios of AsA/DHA and GSH/GSSG, compared with control. Above results suggested that pre-

Table 2. Effect of $30 \mu \mathrm{M} \mathrm{Ce}\left(\mathrm{NO}_{3}\right)_{3}$ on the activities of AsA-GSH cycle enzymes and the ratios of AsA/DHA and GSH/GSSG in the roots of maize seedlings under salt stress

\begin{tabular}{|l|c|c|c|}
\hline \multicolumn{1}{|c|}{ Treatments } & $\begin{array}{c}\text { APX } \\
{\left[\mathrm{U} \mathrm{mg}^{-1} \text { (protein) }\right]}\end{array}$ & $\begin{array}{c}\text { GR } \\
{\left[\mathrm{U} \mathrm{mg}^{-1} \text { (protein) }\right]}\end{array}$ & $\begin{array}{c}\text { DHAR } \\
{\left[\mathrm{U} \mathrm{mg}^{-1} \text { (protein) }\right]}\end{array}$ \\
\hline Control & $1.50 \pm 0.18 \mathrm{~d}$ & $0.93 \pm 0.13 \mathrm{c}$ & $1.38 \pm 0.15 \mathrm{c}$ \\
\hline $\mathrm{Ce}$ & $1.83 \pm 0.20 \mathrm{c}$ & $1.26 \pm 0.13 \mathrm{~b}$ & $1.79 \pm 0.17 \mathrm{~b}$ \\
\hline $\mathrm{NaCl}$ & $2.25 \pm 0.22 \mathrm{~b}$ & $0.60 \pm 0.07 \mathrm{~d}$ & $0.90 \pm 0.10 \mathrm{~d}$ \\
\hline $30 \mu \mathrm{M} \mathrm{Ce}+\mathrm{NaCl}$ & $2.70 \pm 0.31 \mathrm{a}$ & $1.56 \pm 0.20 \mathrm{a}$ & $2.10 \pm 0.21 \mathrm{a}$ \\
\hline \multicolumn{1}{|c|}{ Treatments } & $\begin{array}{c}\text { MDHAR } \\
{\left[\mathrm{U} \mathrm{mg}{ }^{-1}(\mathrm{protein})\right]}\end{array}$ & AsA/DHA & GSH/GSSG \\
\hline $\mathrm{Control}$ & $0.81 \pm 0.09 \mathrm{~d}$ & $22.6 \pm 2.47 \mathrm{~b}$ & $23.1 \pm 2.33 \mathrm{~b}$ \\
\hline $\mathrm{Ce}$ & $1.10 \pm 0.12 \mathrm{c}$ & $24.9 \pm 2.83 \mathrm{a}$ & $25.2 \pm 3.02 \mathrm{a}$ \\
\hline $\mathrm{NaCl}$ & $1.40 \pm 0.13 \mathrm{~b}$ & $18.0 \pm 2.06 \mathrm{~d}$ & $17.7 \pm 1.90 \mathrm{~d}$ \\
\hline $30 \mu \mathrm{M} \mathrm{Ce}+\mathrm{NaCl}$ & $1.84 \pm 0.20 \mathrm{a}$ & $20.3 \pm 2.71 \mathrm{c}$ & $21.0 \pm 2.84 \mathrm{c}$ \\
\hline
\end{tabular}

Note: The plants were treated as follows: Control, full-strength Hoagland's solution; $\mathrm{NaCl}, 100 \mathrm{mM}$ $\mathrm{NaCl} ; 30 \mu \mathrm{M} \mathrm{Ce}+\mathrm{NaCl}, 30 \mu \mathrm{M} \mathrm{Ce}\left(\mathrm{NO}_{3}\right)_{3}+100 \mathrm{mM} \mathrm{NaCl}$. The plants were pretreated with $30 \mu \mathrm{M}$ $\mathrm{Ce}\left(\mathrm{NO}_{3}\right)_{3}$ for $12 \mathrm{~h}$, and then exposed to $100 \mathrm{mM} \mathrm{NaCl}$ for $48 \mathrm{~h}$. Values represent mean \pm standard deviations (SD) of five replicates for each treatment, different letters indicate statistical difference at $P<0.05$ in the same column. 
treatment with $\mathrm{Ce}\left(\mathrm{NO}_{3}\right)_{3}$ could regulate the redox state of ascorbate and glutathione in the roots of maize seedlings under salt stress.

\section{Effects of $\mathrm{Ce}\left(\mathrm{NO}_{3}\right)_{3}$ on $\mathrm{MDA}$ content and EL in the roots of maize seedlings under salt stress}

Compared with control, salt stress increased MDA content and EL by $130 \%$ and $162.8 \%$, respectively (Table 3). Compared to salt stress alone, application of $\mathrm{Ce}\left(\mathrm{NO}_{3}\right)_{3}$ to $\mathrm{NaCl}-$ treated seedlings decreased MDA content and EL by $34.8 \%$ and $36.6 \%$ after $48 \mathrm{~h}$ of treatment, respectively. Meanwhile, pretreatment with $\mathrm{Ce}\left(\mathrm{NO}_{3}\right)_{3}$ alone also significantly decreased MDA content and EL, compared to control. These results suggested that pretreatment with $\mathrm{Ce}\left(\mathrm{NO}_{3}\right)_{3}$ has important role for acquisition of salt tolerance in the roots of maize seedlings.

\section{Effects of $\mathrm{Ce}\left(\mathrm{NO}_{3}\right)_{3}$ on plant height, root dry weight and aboveground dry weight under salt stress}

Compared with control, salt stress decreased plant height, root dry weight and aboveground dry weight by $27.5 \%, 40.7 \%$ and $36.9 \%$, respectively (Table 4 ). Compared to salt

Table 3. Effect of $30 \mu \mathrm{M} \mathrm{Ce}\left(\mathrm{NO}_{3}\right)_{3}$ on MDA content and EL in the roots of maize seedlings under salt stress

\begin{tabular}{|l|c|c|}
\hline \multicolumn{1}{|c|}{ Treatments } & MDA [nmol g-1 (f.m.) & EL [\%] \\
\hline Control & $3.0 \pm 0.42 \mathrm{c}$ & $7.8 \pm 0.90 \mathrm{c}$ \\
\hline $\mathrm{Ce}$ & $2.2 \pm 0.29 \mathrm{~d}$ & $5.0 \pm 0.55 \mathrm{~d}$ \\
\hline $\mathrm{NaCl}$ & $6.9 \pm 0.87 \mathrm{a}$ & $20.5 \pm 2.15 \mathrm{a}$ \\
\hline $30 \mu \mathrm{M} \mathrm{Ce}+\mathrm{NaCl}$ & $4.5 \pm 0.54 \mathrm{~b}$ & $13.0 \pm 1.60 \mathrm{~b}$ \\
\hline
\end{tabular}

Note: The plants were treated as Table 2. The plants were pretreated with $30 \mu \mathrm{M} \mathrm{Ce}\left(\mathrm{NO}_{3}\right)_{3}$ for $12 \mathrm{~h}$, and then exposed to $100 \mathrm{mM} \mathrm{NaCl}$ for $48 \mathrm{~h}$. Values represent mean \pm standard deviations (SD) of five replicates for each treatment, different letters indicate statistical difference at $P<0.05$ in the same column.

Table 4. Effect of $30 \mu \mathrm{M} \mathrm{Ce}\left(\mathrm{NO}_{3}\right)_{3}$ on plant height, root dry weight and shoot dry weight of maize seedlings under salt stress

\begin{tabular}{|l|c|c|c|}
\hline \multicolumn{1}{|c|}{ Treatments } & Plant height $[\mathrm{cm}]$ & $\begin{array}{c}\text { Dry weight of root } \\
{\left[\mathrm{g} \mathrm{plant}^{-1} \text { ] }\right.}\end{array}$ & $\begin{array}{c}\text { Dry weight of shoot } \\
\text { [g plant }\end{array}$ \\
\hline Control & $19.3 \pm 2.36 \mathrm{~b}$ & $0.27 \pm 0.04 \mathrm{~b}$ & $1.11 \pm 0.14 \mathrm{~b}$ \\
\hline $\mathrm{Ce}$ & $21.5 \pm 3.15 \mathrm{a}$ & $0.33 \pm 0.04 \mathrm{a}$ & $1.27 \pm 0.19 \mathrm{a}$ \\
\hline $\mathrm{NaCl}$ & $14.0 \pm 1.52 \mathrm{~d}$ & $0.16 \pm 0.03 \mathrm{~d}$ & $0.70 \pm 0.09 \mathrm{~d}$ \\
\hline $30 \mu \mathrm{M} \mathrm{Ce}+\mathrm{NaCl}$ & $17.2 \pm 1.77 \mathrm{c}$ & $0.22 \pm 0.04 \mathrm{c}$ & $0.92 \pm 0.11 \mathrm{c}$ \\
\hline
\end{tabular}

Note: The plants were treated as Table 2. The plants were pretreated with $30 \mu \mathrm{M} \mathrm{Ce}\left(\mathrm{NO}_{3}\right)_{3}$ for $12 \mathrm{~h}$, and then exposed to $100 \mathrm{mM} \mathrm{NaCl}$ for $168 \mathrm{~h}$. Values represent mean \pm standard deviations (SD) of five replicates for each treatment, different letters indicate statistical difference at $P<0.05$ in the same column. 
Table 5. The correlation between growth parameters and enzymes, MDA and EL under the treatment of Ce plus salt stress

\begin{tabular}{|l|c|c|c|c|c|c|}
\hline & APX & GR & DHAR & MDHAR & MDA & EL \\
\hline Plant height & 0.9524 & 0.9376 & 0.9826 & 0.9643 & -0.9942 & -0.9586 \\
\hline Dry weight of root & 0.9663 & 0.9257 & 0.9746 & 0.9555 & -0.9882 & -0.9811 \\
\hline Dry weight of shoot & 0.9317 & 0.9266 & 0.9633 & 0.9541 & -0.9636 & -0.9779 \\
\hline
\end{tabular}

Note: The data in this table are the correlation coefficients between corresponding parameters.

stress alone, application of $\mathrm{Ce}\left(\mathrm{NO}_{3}\right)_{3}$ to NaCl-treated seedlings increased plant height, root dry weight and aboveground dry weight by $22.9 \%, 37.5 \%$ and $31.4 \%$ after $48 \mathrm{~h}$ of treatment, respectively. Meanwhile, pretreatment with $\mathrm{Ce}\left(\mathrm{NO}_{3}\right)_{3}$ alone also significantly increased plant height, root dry weight and aboveground dry weight, compared to control. These results suggested that pretreatment with $\mathrm{Ce}\left(\mathrm{NO}_{3}\right)_{3}$ has important role for acquisition of salt tolerance in the roots of maize seedlings.

The correlation between growth parameters and enzymes, MDA and EL under the treatment of $\mathrm{Ce}\left(\mathrm{NO}_{3}\right)_{3}$ plus salt stress

There was positive correlation between plant height, dry weights of root and shoot and enzymes in AsA-GSH cycle under the treatment of Ce plus salt stress (Table 5). However, there was negative correlation between plant height, dry weights of root and shoot and MDA, EL under the treatment of $\mathrm{Ce}\left(\mathrm{NO}_{3}\right)_{3}$ plus salt stress. Above correlation analysis further indicated that $\mathrm{Ce}\left(\mathrm{NO}_{3}\right)_{3}$ could improve the growth and salt tolerance of maize seedlings by enhancing the activity of AsA-GSH cycle in the roots.

\section{Discussion}

Several studies showed that Ce could make an influence on redox mechanisms by regulating the antioxidant defense system in plants under stresses, which mainly focused on antioxidant enzymes, including SOD, POD and CAT (Wu et al. 2014; Rossi et al. 2016). However, the influence of $\mathrm{Ce}$ on the antioxidant enzymes in AsA-GSH cycle and nonenzymatic antioxidants ascorbate and glutathione in the roots of maize under salt stress is still unclear.

Ascorbate is an important redox compound in plants, which can regulate the redox status of plant cells and fight against oxidative damage induced by stresses. The cellular ratio of AsA/DHA can be determined by AsA-GSH cycle through APX, DHAR and MDHAR. It has been documented that salt stress could regulate the ratio of AsA/DHA through APX, DHAR and MDHAR in many plants, such as tomato, mung bean and maize (Diao et al. 2014; Shan and Zhao 2014; Shan et al. 2014). In our previous study, the results showed that salt stress made a significant decrease in the ratio of AsA/DHA and significant increases in the activities of APX, DHAR and MDHAR in the leaves of maize (Shan et al. 2014). However, the effect of salt stress on the ratio of AsA/DHA and the activities 
of APX, DHAR and MDHAR in the roots of maize is still unknown. In the present study, our results showed that salt stress also made a significant decrease in the ratio of AsA/ DHA and significant increases in the activities of APX and MDHAR in the roots of maize, which was consistent with our previous results in maize leaves (Shan et al. 2014). However, our present study showed that salt stress made a significant decrease in the activity of DHAR in maize roots, which was not consistent with our previous results in maize leaves (Shan et al. 2014). The difference in the effect of salt stress on the activity of DHAR between roots and leaves of maize seedlings may be due to organ specificity. It has also been documented that Ce could protect Brassica napus and maize crop against salt stress (Qu et al. 2013; Rossi et al. 2016). However, up to now, there is no report for the effect of $\mathrm{Ce}$ on the ratio of AsA/DHA and the activities of APX, DHAR and MDHAR in the roots of maize. In the present study, our results showed that Ce significantly increased the ratio of AsA/DHA in the roots of maize under salt stress by up-regulating the activities of APX, DHAR and MDHAR, which indicated that Ce could up-regulate the redox state of ascorbate through ascorbate-related enzymes in AsA-GSH cycle.

Glutathione is another important redox compound in plants, which can regulate the redox status of plant cells and fight against oxidative damage induced by stresses. The cellular ratio of GSH/GSSG can be determined by AsA-GSH cycle through GR. It has been documented that salt stress could regulate the ratio of GSH/GSSG through GR in many plants, such as tomato, mung bean and maize (Diao et al. 2014; Shan and Zhao 2014; Shan et al. 2014). In our previous study, the results showed that salt stress made a significant decrease in the ratio of GSH/GSSG and increase in the activity of GR in the leaves of maize (Shan et al. 2014). However, the effect of salt stress on the ratio of GSH/ GSSG and the activity of GR in the roots of maize is still unknown. In the present study, our results showed that salt stress also made a significant decrease in the ratio of GSH/ GSSG and increase in the activity of GR in the roots of maize, which was consistent with our previous results in maize leaves (Shan et al. 2014). It has been documented that Ce could protect Brassica napus and maize crop against salt stress (Qu et al. 2013; Rossi et al. 2016). However, up to now, there is no report for the effect of Ce on the ratio of GSH/ GSSG and the activity of GR in the roots of maize. In the present study, our results showed that Ce significantly increased the ratio of GSH/GSSG in the roots of maize under salt stress by up-regulating the activity of GR, which indicated that Ce could up-regulate the redox state of glutathione through GR in AsA-GSH cycle.

Many studies indicated that salt stress induced oxidative damage to plants, indicated by MDA content and EL (Liu et al. 2012; Hu et al. 2012; Yousuf et al. 2017). In the present study, our results also indicated that salt stress induced oxidative damage to the roots of maize by markedly increasing MDA content and EL, which was consistent with previous studies (Liu et al. 2012; Hu et al. 2012; Yousuf et al. 2017). It has been documented that Ce could protect plants against salt stress by improving the efficiency of the photosynthetic apparatus (Qu et al. 2013; Rossi et al. 2016). Several studies also showed that Ce could protect plants against copper stress and cadmium stress by alleviating oxidative damage (Liu et al. 2016; Wu et al. 2014). However, knowledge on how Ce affect the oxidative damage induced by salt stress is almost empty. In the present study, our results 
suggested that Ce alleviate the oxidative damage induced by salt stress in the roots of maize seedlings, which was consistent with previous results under copper stress and cadmium stress (Wu et al. 2014; Liu et al. 2016). Combining above results related the effect of Ce on AsA-GSH cycle and the ratios of AsA/DHA and GSH/GSSG, our present study indicated that $\mathrm{Ce}$ could alleviate the salt stress-induced oxidative damage to the roots of maize seedlings by increasing the ratios of AsA/DHA and GSH/GSSG through AsA-GSH cycle. Besides, our results also showed that Ce markedly improved the plant height and dry weight of root and aboveground, which further proved that Ce could protect maize seedlings against salt stress by alleviating salt stress-induced oxidative damage through AsA-GSH cycle. Therefore, our findings provide theory evidence for the application of $\mathrm{Ce}$ in the production of maize crop grown on saline soil.

In conclusion, our results clearly suggest that Ce regulates the redox states of ascorbate and glutathione by increasing the activities of APX, GR, DHAR and MDHAR in the roots of maize seedlings, which, in turn, enhances the antioxidant ability and protects maize seedlings against salt stress-induced oxidative stress These results provide new knowledge to the antioxidant metabolism in maize crop regulated by Ce under salt stress.

\section{Acknowledgement}

This study was funded by the Science and Technology Program of Henan Province (142102110041).

\section{References}

Bradford, M.M. 1976. A rapid and sensitive method for the quantitation of microgram quantities of protein utilizing the principle of protein-dye binding. Anal. Biochem. 72:248-254.

Dai, H., Shan, C., Zhao, H., Jia, G., Chen, D. 2016. Lanthanum improves the cadmium tolerance of Zea mays seedlings by the regulation of ascorbate and glutathione metabolism. Biol. Plant. doi:10.1007/s10535-0160669-4

Dalton, D.A., Russell, S.A., Hanus, F.J., Pascoe, G.A., Evans, H.J. 1986. Enzymatic reactions of ascorbate and glutathione that prevent peroxide damage in soybean root nodules. Proc. Natl Acad. Sci. USA 83:38113815 .

Diao, M., Ma, L., Wang, J., Cui, J., Fu, A., Liu, H. 2014. Selenium promotes the growth and photosynthesis of tomato seedlings under salt stress by enhancing chloroplast antioxidant defense system. J. Plant Growth Regul. 33:671-682.

Grace, S.C., Logan, B.A. 1996. Acclimation of foliar antioxidant systems to growth irradiance in three broadleaved evergreen species. Plant Physiol. 112:1631-1640.

Griffith, O.W. 1980. Determination of glutathione and glutathione disulfide using glutathione reductase and 2-vinylpyridine. Anal. Biochem. 106:207-212.

Hodges, D.M., Andrews, C.J., Johnson, D.A., Hamilton, R.I. 1996. Antioxidant compound responses to chilling stress in differentially sensitive inbred maize lines. Plant Physiol. 98:685-692.

Hodges, M.D., DeLong, J.M., Forney, C.F., Prange, R.K. 1999. Improving the thiobarbituric acid-reactivesubstances assay for estimating lipid peroxidation in plant tissues containing anthocyanin and other interfering compounds. Planta 207:604-611.

Hu, M., Shi, Z., Zhang, Z., Zhang, Y., Li, H. 2012. Effects of exogenous glucose on seed germination and antioxidant capacity in wheat seedlings under salt stress. Plant Growth Regul. 68:177-188.

Jouyban, Z. 2012. The effects of salt stress on plant growth. Tech. J. Engin. App. Sci. 2:7-10. 
Liu, R., Shan, C., Gao, Y., Wang, J., Xu, Z., Zhang, L., Ma, W., Tan, R. 2016. Cerium improves the copper tolerance of turf grass Poa pratensis by affecting the regeneration and biosynthesis of ascorbate and glutathione in leaves. Braz. J. Bot. 39:779-785.

Liu, S.G., Zhu, D.Z., Chen, G.H., Gao, X.Q., Zhang, X.S. 2012. Disrupted actin dynamics trigger an increment in the reactive oxygen species levels in the Arabidopsis root under salt stress. Plant Cell Rep. 31:1219-1226.

Mao, C.X., Chen, M.M., Wang, L., Zou, H., Liang, C.J., Wang, L.H., Zhou, Q. 2012. Protective effect of cerium ion against ultraviolet $\mathrm{B}$ radiation-induced water stress in soybean seedlings. Biol. Trace Elem. Res. 146:381-387.

Miyake, C., Asada, K. 1992. Thylakoid-bound ascorbate peroxidase in spinach chloroplasts and photoreduction of its primary oxidation product monodehydroascorbate radicals in thylakoids. Plant Cell Physiol. 33:541553.

Muchate, N.S., Nikalje, G.C., Rajurkar, N.S., Suprasanna, P., Nikam, T.D. 2016. Plant salt stress: adaptive responses, tolerance mechanism and bioengineering for salt tolerance. Bot. Rev. 82:371-406.

Nakano, Y., Asada, K. 1981. Hydrogen peroxide is scavenged by ascorbate specific peroxidase in spinach chloroplasts. Plant Cell Physiol. 22:867-880.

Qu, C., Liu, C., Guo, F., Hu, C., Ze, Y., Li, C., Zhou, Q., Hong, F. 2013. Improvement of cerium on photosynthesis of maize seedlings under a combination of potassium deficiency and salt stress. Biol. Trace Elem. Res. 155:104-113.

Rossi, L., Zhang, W., Lombardini, L., Ma, X. 2016. The impact of cerium oxide nanoparticles on the salt stress responses of Brassica napus L. Environmental Pollution 219:28-36.

Shan, C., Liu, H., Zhao, L., Wang, X. 2014. Effects of exogenous hydrogen sulfide on the redox states of ascorbate and glutathione in maize leaves under salt stress. Biol. Plant. 58:169-173.

Shan, C., Zhao, X. 2014. Effects of lanthanum on the ascorbate and glutathione metabolism of Vigna radiate seedlings under salt stress. Biol. Plant. 58:595-599.

Shan, C., Zhou, Y., Liu, M. 2015. Nitric oxide participates in the regulation of the ascorbate-glutathione cycle by exogenous jasmonic acid in the leaves of wheat seedlings under drought stress. Protoplasma 252:13971405.

Wu, M., Wang, P.Y., Sun, L.G., Zhang, J.J., Yu, J., Wang, Y.W., Chen, G.X. 2014. Alleviation of cadmium toxicity by cerium in rice seedlings is related to improved photosynthesis, elevated antioxidant enzymes and decreased oxidative stress. Plant Growth Regul. 74:251-260.

Yousuf, P.Y., Ahmad, A., Ganie, A.H., Sareer, O., Krishnapriya, V., Aref, I.M., Iqbal, M. 2017. Antioxidant response and proteomic modulations in Indian mustard grown under salt stress. Plant Growth Regul. 81:31-50.

Zhao, L.Q., Zhang, F., Guo, J.K., Yang, Y.L., Li, B.B., Zhang, L.X. 2004. Nitric oxide functions as a signal in salt resistance in the calluses from two ecotypes of reed. Plant Physiol. 134:849-857. 